\title{
A leitura proficiente de enunciados e de alternativas das questões da prova do Enem 2011: uma reflexão necessária
}

\author{
Isabela do Nascimento Pacheco
}

Universidade de Taubaté - UNITAU

\begin{abstract}
Resumo
A educação nacional reclama por urgentes transformações, principalmente quando detectamos problemas relacionados com as habilidades leitoras dos aprendizes, comprometendo seu desempenho na resolução de questões que lhes são propostas em diferentes avaliações. Partindo de observação junto a dezenove alunos do $3^{\circ}$ ano do Ensino Médio, rede pública paulista, do período noturno, com os quais trabalhei a resolução e interpretação de duas situações-problema da Prova do ENEM 2011, na Área de Linguagens e Códigos e suas Tecnologias, constatei que a grande dificuldade dos mesmos encontra-se na compreensão dos enunciados e suas alternativas propostos pelos problemas da avaliação. Retomando documentos oficiais do ENEM, PCN, bem como autores que abordam a leitura numa concepção sociocognitiva e construtivista, evidencia-se a necessidade de implementação de novas metodologias e estratégias didáticas com foco na proficiência leitora dos jovens.
\end{abstract}

Palavras-chave

Ensino; Enunciado; Leitura; Metodologia; Estratégias

\begin{abstract}
Education in Brazil needs urgent transformations, mainly concerning problems related to learners' reading skills, as their performance in solving/answering questions that are on standardized tests can be very disappointing/ unsatisfactory. For this study, I made observations on the performance of nineteen third-year high-school students from the night class in the Paulista public system, with whom I worked on the resolution and interpretation of two situation-problem questions on the ENEM 2011 test, in Languages and Codes and Their Technologies. I verified that the biggest difficulty of those learners lies in the comprehension of the directions in the exam problems. From a reading of ENEM and PCN official documents, as well as authors that broach the reading process in a constructivist and sociocognitive conception, it becomes evident that new methodologies and didactic strategies need to be implemented, focusing on the young people's reading proficiency.

Keywords

Teaching; Learning; Reading; Methodology; Strategies.
\end{abstract}




\section{APRESENTAÇÃO}

Ao observar dados referentes à Prova Brasil e SAEB (BRASIL, 2008), percebese a porcentagem razoavelmente alta de acertos quando os alunos localizam informações explícitas em um texto $-72 \%$ de alunos do $5^{\circ}$ Ano do Ensino Fundamental e $76 \%$ dos alunos do $9^{\circ}$ Ano do mesmo nível de ensino. Na distinção de um fato da opinião relativa a ele, no entanto, o índice cai significativamente - $36 \%$ para o $5^{\circ}$ Ano e $58 \%$ para o $9^{\circ}$ Ano do Ensino Fundamental. Alarmantes se apresentam os resultados no que concerne à variação linguística (24\% de acertos para alunos do $5^{\circ}$ Ano e $33 \%$ para alunos do $9^{\circ}$ Ano, Ensino Fundamental), apontando para sérios problemas demonstrados ao não identificarem as marcas linguísticas que evidenciam locutor e interlocutor de um texto, habilidade essencial para a sua compreensão significativa.

A partir de dados desta natureza, analiso resultados do levantamento sobre as dificuldades dos educandos na compreensão de dois itens da prova do ENEM 2011, fundamentando-me nos estudos sobre leitura e as habilidades envolvidas no processo de leitura, numa perspectiva sociocognitiva e nas situações-problema da avaliação.

O objetivo geral do artigo é contribuir para a reflexão do professor do Ensino Médio no sentido do desenvolvimento das habilidades de leitura dos alunos atrelado a sua prática pedagógica, focando a adequação na proficiência leitora do sujeito.

\section{DA MEMORIZAÇÃO ÀS COMPETÊNCIAS E HABILIDADES}

A leitura deve ser ensinada na escola, é "questão de escola, de projeto curricular e de todas as matérias (existe alguma em que não seja necessário ler?)" (SOLÉ, 1998, p.19)

Até os anos 20, no Brasil, o ensino era concebido partindo do pressuposto de que a criança já teria que ter a visão adulta dos fatos e conhecimentos valorizados e ensinados na escola. A técnica da memorização por ela mesma era então altamente posta em evidência, pois se tinha a ideia de que a memória, e somente ela, era o canal privilegiado para que as informações fossem compreendidas e apreendidas pelas crianças. As escolas ocupavam, nessa época, posição de destaque no cenário da nação, eram extremamente seletistas e lembravam o modelo educacional concebido pelo mundo medieval. Daí a cultura permanecer reduzida ao acesso de muito poucos, estando 
a classe popular, em sua imensa maioria, alijada deste processo. Quando muito, para ela eram selecionadas as escolas que ofereciam os famosos cursos profissionalizantes, preparando-a para o trabalho operariado, enquanto o conhecimento acadêmico ficava restrito às classes ricas, perpetuando o que já vinha acontecendo desde a educação jesuítica.

"Nos anos 20, entretanto, chega ao Brasil a visão da criança não como um adulto em miniatura, mas como um ser com características cognitivas distintas - uma visão do aprendiz como um ser ativo que constrói seu próprio conhecimento." (WEISZ, 2002, p.30) Este movimento é conhecido como Escola Nova, nome que abarcou vários momentos educacionais, cujos ícones foram Dewey e Claparède, Montessori e Freinet. Divergentes entre si em algumas questões tinham um ponto de defesa em comum: "a valorização do indivíduo como ser livre, ativo e social” (WEISZ, 2002, p.30).

Um dos vieses elaborados nessa época foi o conhecido como aprendizagem pela descoberta, ou seja, a escola teria que criar condições de todos os matizes para despertar o interesse dos alunos, incitando-os a fazerem descobertas por eles mesmos, buscando informações a partir de suas vivências, o que eliminava a necessidade de um currículo geral de ensino. Levada a vários tipos de interpretações equivocadas e distorcidas, ou mesmo por não contar com profissionais instrumentalizados para trabalhar segundo este preceito, essa visão educativa acabou por provocar e incentivar uma onda de práticas pedagógicas vazias, espontaneístas, utilizadas ao sabor do momento e do improviso.

Ao colocar o foco exclusivamente no processo de aprendizagem, o movimento da Escola Nova deixou de lado o produto dessa aprendizagem. (...) de uma situação em que o aluno deveria receber o conteúdo por pura transmissão, evoluiu-se para uma outra, na qual o conteúdo a ser aprendido deixava de ter importância. A ideia predominante era que o papel do ensino deveria ser o de criar possibilidades para que o aluno pudesse aprender a aprender, não importava exatamente o quê. (WEISZ, 2002, p.31)

A pedagogia da escola nova não favoreceu em nada as crianças vindas de classes sociais mais inferiores, o que a tornou alvo de duras críticas no Brasil, principalmente na década de 1970. Além disso, ao não privilegiar o produto da aprendizagem, este modelo fazia recomendações pedagógicas de maneira muito geral e abrangente: “é importante trabalhar em grupo, desenvolver a cooperação, a moralidade, a criatividade, estimular a curiosidade" (WEISZ, 2002, p.31). Contudo, na prática, desenvolvia-se um 
ensino extremamente tradicional, como sempre fora. Segundo WEISZ (2002), funcionando mais efetivamente para o ensino infantil, os métodos da Escola Nova deixaram os professores em geral, de outros níveis de ensino, numa situação conflitiva, já que empregavam, até então, métodos de ensino cristalizados, baseados tão somente na memória.

No início do século XX, Piaget lança um novo olhar sobre a aprendizagem. Ainda que pautado em outra realidade, que não a brasileira, Piaget foi muito estudado no Brasil, visto sua enorme contribuição no campo cognitivo, auxiliando-nos a entender o processamento da aquisição de saberes, mostrando-nos que estes não vêm de fora para dentro do cérebro humano. A partir de sua teoria, que tenta explicar como se avança de um conhecimento menos elaborado para outro estágio mais sofisticado que o anterior, muitas outras teorias foram construídas e colocadas em prática nas salas de aula, a título de experiência, fazendo de nosso sistema educacional uma verdadeira colcha de retalhos. Muitas delas fracassaram. Sofremos até hoje com este caráter laboratorial imposto aos sistemas educacionais, pois que, de quando em quando, novas metodologias de ensino são testadas e, ao final, caem no vazio e no amargo de mais uma experiência extremamente frustrada.

Muitas iniciativas da esfera pública de ensino não obtêm sucesso, já que as reformas exigidas atualmente são de caráter estrutural e não superficial, como costumam ser implantadas. Falta de qualificação adequada, formação inicial extremamente deficitária, desrespeito social instalado levam o Brasil a ocupar as últimas posições no ranking educacional mundial.

As reformas educacionais institucionalizadas vão se sucedendo, ora avançando, ora retrocedendo em ideias e aplicações. Nota-se, entretanto, que, de maneira bastante lenta, a educação caminha à medida que a nação se desenvolve.

O que conseguimos ver no quadro geral da educação é que os discursos estão na contramão da prática, pois que impostos como políticas de governo e não como políticas de Estado. Verifica-se que o processo educativo não sofreu profundas alterações como deveria e, quando enfrentamos um movimento mais radical, as tendências são polarizadas, caindo em perigos que, perpetuados, não chegarão ao nível da aprendizagem efetiva dos alunos, nosso objetivo primeiro. Apesar de estar claro que 
não há ensino desvinculado de um momento social, político, econômico e social, ainda nos deparamos com práticas docentes desvinculadas de toda esta contextualização, o que fica claro ao analisarmos as maiores dificuldades enfrentadas pelos alunos quando da resolução de questões de provas, especialmente de avaliações de abrangência nacional como os grandes vestibulares e o ENEM.

\section{A LEITURA DOS ENUNCIADOS E ALTERNATIVAS DA AVALIAÇÃO DO ENEM 2011}

Atualmente, é comum depararmo-nos com alunos que não demonstram as habilidades necessárias no que se refere à interpretação dos enunciados das situaçõesproblema $^{1}$ que lhes são propostas. Apresentados de maneira simples, escritos na ordem direta, não são compreendidos na maioria das vezes, o que provoca frustração e erro na tentativa de resolução da proposta enunciativa. Os professores do Ensino Médio, de maneira geral, precisam voltar-se para esta questão, articulando habilidades de leitura que se tornem hábitos permanentes dos alunos, bem como ressignificando a própria prática pedagógica em sala de aula, com vistas à proficiência leitora dos aprendizes.

Aqueles enunciados que apenas sugerem a decodificação de palavras simples, dispostas em ordem gramatical direta e, portanto, bastante próxima ao oral, mantêm ainda um percentual de acertos. Estes textos, além de tradicionalmente cristalizados, não oferecem maior grau de complexidade, levando o aluno a acionar estruturas mentais cognitivas básicas. Na contramão, aqueles que propõem a leitura inferente, demandando que estruturas mentais complexas sejam acionadas, que necessitam da ativação de préconhecimentos, são dificilmente resolvidos pelos examinandos que, por vezes, conhecem o assunto, porém, não compreendem o enunciado da situação-problema.

Segundo Löbler e Flôres (2010, p. 181), “aprofundar o conhecimento a respeito da relação fulcral entre ler e compreender é uma necessidade decorrente de sua dissociação em grande número de situações usuais." Para validar tal assertiva, vejamos o resultado de duas situações-problema selecionadas da prova do ENEM 2011(Área de Linguagens, Códigos e suas Tecnologias) junto a dezenove alunos de escola pública paulista do Ensino Médio.

\footnotetext{
${ }^{1}$ O ENEM não usa o termo "questão", mas "situação problema".
} 


\section{QUESTÃO 98}

Quem é pobre, pouco se apega, é um giro-o-giro no vago dos gerais, que nem os pássaros de rios e lagoas. O senhor vê: o Zé-Zim, o melhor meeiro meu aqui, risonho e habilidoso. Pergunto: - Zé-Zim, por que é que você não cria galinhas-d'angola, como todo o mundo faz? - Quero criar nada não... - mre deu resposta: - Eu gosto muito de mudar... [...] Belo um dia, ele tora. Ninguém discrepa. Eu, tantas, mesmo digo. Eu dou proteção. [...] Essa não faltou também à minha mãe, quando eu era menino, no sertãozinho de minha terra. [...] Gente melhor do lugar eram todos dessa família Guedes, Julião Guedes; quando saíram de lá, nos trouxeram junto, minha mãe e eu. Ficamos existindo em território baixio da Sirga, da outra banda, ali onde o de-Janeiro vai no São Francisco, o senhor sabe.”

(ROSA. J.G. Grande Sertão: Veredas. Rio de Janeiro: José Olympio -fragmento)

Na passagem citada, Riobaldo expõe uma situação decorrente de uma desigualdade social típica das áreas rurais brasileiras marcadas pela concentração de terras e pela relação de dependência entre agregados e fazendeiros. No texto, destaca-se essa relação porque o personagem-narrador

A) relata a seu interlocutor a história de Zé-Zim, demonstrando pouca disposição em ajudar seus agregados, uma vez que superou essa condição graças à sua força de trabalho.

B) descreve o processo de transformação de um meeiro - espécie de agregado - em proprietário de terra.

C) denuncia a falta de compromisso e a desocupação dos moradores, que pouco se envolvem no trabalho da terra.

D) mostra como a condição material da vida do sertanejo é dificultada pela sua dupla condição de homem livre e, ao mesmo tempo, dependente.

E) mantém o distanciamento narrativo condizente com sua posição social, de proprietário de terras.

(Prova ENEM 2011, Caderno Amarelo, $2^{\circ}$ dia, página 7)

Resposta correta: D

Habilidades $^{2}$ avaliadas: H17: Reconhecer a presença de valores sociais e humanos atualizáveis e permanentes no patrimônio literário nacional;

H25: Identificar, em textos de diferentes gêneros, as marcas linguísticas que singularizam as variedades linguísticas sociais, regionais e de registro;

H26: Relacionar as variedades linguísticas a situações específicas de uso social.

Para iniciar o procedimento de estudo do texto, primeiramente, li o texto com os alunos, que, de maneira geral, consideraram-no "muito difícil", apontando obstáculos para compreender seu enunciado, "porque a gente lê o texto e na hora de responder é tudo diferente", manifestou-se um deles. Dos dezenove educandos que participaram desta atividade, onze afirmaram não terem entendido o texto e o enunciado e um deles ainda apontou para a não compreensão das alternativas. Seis alunos não responderam à

\footnotetext{
2 "Quando o que se busca é o desenvolvimento das potencialidades humanas, a construção de identidade pessoal e da cidadania, é natural que se procure reconhecer as motivações mais radicais das questões usualmente formuladas nos âmbitos das disciplinas. É possível, então, mapear um espectro de formas de manifestação de tais potencialidades, que podem ser denominadas habilidades.” (BRASIL, 2009, p.46)
} 
questão, um deles disse não ter entendido "nada" e outro colocou não ter conhecimento das palavras empregadas no texto.

Discutindo o significado dos termos compreender e decifrar, Löbler e Flôres (2010) citam Dascal (2006), que afirma que tais termos não podem ser equiparados, uma vez que decifrar consiste em "descobrir um código" e as regras "da compreensão não tendem a ser algorítimas e, sim, heurísticas". Embora interligados, são conceitos distintos. "Sem dúvida, para que se chegue à compreensão de um texto, é possível e necessário saber o significado dos termos nele empregados, porém acreditar que somente com o significado das palavras a compreensão será obtida é ilusório" (Löbler e Flores, 2010, p 184).

É importante esclarecer que estes alunos frequentam uma escola pública estadual paulista, $3^{\circ}$ ano do Ensino Médio, regular, noturno, turma com 25 alunos, com idades que variam entre 18 e 30 anos. Sendo trabalhadores, esses aprendizes mostram crônicas lacunas no que se refere à alfabetização, com repercussão negativa em toda a sua trajetória escolar, caracterizada por grandes e graves percalços.

A observação deu-se em uma aula de Língua Portuguesa, que tinha por principal tema a Competência Leitora dos alunos em textos diversos, objetivando a observação das habilidades de leitura desenvolvidas pelos sujeitos durante os oito anos de escolaridade básica.

É significativo o fato de $57,8 \%$ dos alunos apontarem para o não entendimento do texto e do enunciado da situação-problema, considerando-se que o universo de alunos pesquisado estava já no final do ano de conclusão da terceira série do Ensino Médio.

A tarefa de leitura proposta consiste na interpretação de um trecho de romance. Com alto nível de discriminação, os alunos não compreenderam o texto literário, bem como o enunciado da situação-problema e suas alternativas. O desconhecimento das palavras utilizadas no texto foi fator preponderante, e, até por isso, não houve identificação das alternativas e do enunciado com o texto regionalista. Entretanto, o enunciado, face à complexidade do texto, exerce papel essencial, já que o próprio elaborador do item propõe-se a fornecer pistas para a compreensão do excerto.

Quanto ao texto, precisamos considerar vários aspectos: texto-referência da literatura brasileira, autor regionalista consagrado, gênero romance, diálogos corriqueiros inseridos naquele contexto, assim como termos e expressões próprios da região ("giro-o-giro", "vago dos gerais", "Belo um dia, ele tora", "Ficamos existindo em 
território"), vocabulário específico, estruturas frasais inversas ("Gente melhor do lugar eram todos dessa família Guedes...”). É também importante ressaltar que é extremamente necessário que o aluno domine temas como desigualdade social, relação de poder, transpondo-os para auxiliar no entendimento do texto apresentado, que cumpre sua função social. Espera-se que um aluno deste nível e grau de ensino conheça tal obra, mas não é o que vemos acontecer na prática.

Em contrapartida, consultando livros didáticos e mesmo materiais curriculares diversos, como apostilas utilizadas tanto em escolas públicas quanto privadas, encontramos o livro Grande sertão: Veredas, de Guimarães Rosa, como material de trabalho, inclusive com excertos transcritos para análise, à maneira do que foi proposto na avaliação.

O enunciado analisado foi formulado, de acordo com Reinaldo (2006), no nível de composição sequencial injuntiva, contemplando a categoria explicação/justificativa (busca situar as situações propostas, com esclarecimentos que permitem a realização do que se solicita) e, ao mesmo tempo, a categoria determinação (focaliza o fazer, a solicitação de procedimentos a serem realizados pelo examinado). Este tipo de enunciado auxilia no que tange a sua legibilidade, possibilitando que maior número de informações sejam processadas pelo aluno. Ao mesmo tempo, o texto do enunciado do item está redigido na ordem direta, não apresentando problemas mais complexos no tocante ao léxico empregado, requerendo apenas conhecimentos gramaticais básicos que o aluno deste nível de ensino deve ter.

Já em relação às alternativas (apenas uma está correta), construídas na ordem direta, fato que colabora para a compreensão do aluno, percebemos que os verbos das mesmas requerem a habilidade de inferência. Viana (1976) considera que este tipo de verbo (relatar, demonstrar, descrever, denunciar, mostrar, manter) "dá à sentença um caráter descritivo do comportamento desejado, indicando comportamentos termináveis observáveis (comportamentos que se espera que o educando tenha adquirido após certa experiência educacional)" (VIANA, 1976, p.32).

\section{Questão 99}

A discussão sobre "o fim do livro de papel” com a chegada da mídia eletrônica me lembra a discussão idêntica sobre obsolescência do folheto de cordel. Os folhetos talvez não existam mais daqui a 100 ou 200 anos, mas, mesmo que isso aconteça, os poemas de Leandro Gomes de Barros ou Manuel Camilo dos Santos continuarão sendo publicados e lidos - em CD-ROM, em livro eletrônico, em 'chips quânticos', sei lá o quê. O texto é uma espécie de alma imortal, capaz de reencarnar em corpos variados: 
página impressa, livro em Braille, folheto, "coffee-table book", cópia manuscrita, arquivo PDF ... Qualquer texto pode se reencarnar nesses (e em outros) formatos, não importa se é Moby Dick ou Viagem a São Saruê, se é Macbeth ou O livro de piadas de Casseta \& Planeta.

( TAVARES, B. Disponível em http://jornaldaparaiba.globo.com)

Ao refletir sobre a possível extinção do livro impresso e o surgimento de outros suportes em via eletrônica, o cronista manifesta seu ponto de vista, defendendo que

A) o cordel é um dos gêneros textuais, por exemplo, que será extinto com o aumento da tecnologia.

B) o livro impresso permanecerá como objeto cultural veiculador de impressões e de valores culturais.

C) o surgimento da mídia eletrônica decretou o fim do prazer de se ler textos e,m livros e suportes impressos.

D) os textos continuarão vivos e passíveis de reprodução em novas tecnologias, mesmo que os livros desapareçam.

E) Os diversos gêneros.

(Prova ENEM 2011, Caderno Amarelo, $2^{\circ}$ dia, página 7)

\begin{abstract}
Resposta correta: D
Habilidade avaliada: H2: Recorrer aos conhecimentos sobre as linguagens dos sistemas de comunicação e informação para resolver problemas sociais.
\end{abstract}

Com alto grau de discriminação, a tarefa de leitura proposta consiste na identificação de estratégias para o convencimento do leitor. Neste item, dos dezenove participantes da pesquisa, a grande maioria (95\%) considerou a situação-problema muito fácil e apenas um aluno ponderou que "teve dificuldades com algumas palavras". Tal resultado pressupõe que os aprendizes dominem determinadas habilidades de leitura compreensiva como ativação do conhecimento prévio, associação do real com o texto, capacidade de inferência.

Construída na ordem direta e, portanto, propiciando um entendimento muito mais claro para a maior parte dos alunos, a crônica apresenta-se, por si só, como elemento facilitador para a compreensão, visto a proximidade com o leitor, que domina e interage cotidianamente com os temas abordados por este gênero discursivo. Este nem sempre se dá conta de que o emprego de certos termos e de determinadas construções sintáticas possui função persuasiva - "sei lá o quê", provocando a proximidade autor/leitor ao imprimir ao escrito este tom de informalidade. O sucesso ou fracasso do sujeito avaliado está intimamente relacionado "com o maior ou menor acesso deste aos conhecimentos referenciados por meio do processo de lexicalização.” (REINALDO, 2006, p.4) 
Os alunos, no que tange ao enunciado da questão, apresentado também na ordem direta, sem excesso de informação, mostraram, por inferência, dominar o conceito da palavra "suporte" no contexto em que está inserida.

No que se refere às alternativas, colocam-se estruturadas com base, principalmente, em verbos de estado, que não acenam com a possibilidade de movimentação no interior da frase. Este tipo de construção, considerada mais estática, mantém a linha de raciocínio em único parâmetro, não sendo necessário recorrer à ativação de estruturas cognitivas mais complexas para sua compreensão.

Atualmente, recomenda-se a adoção de uma nomenclatura que espelhe o enfoque descritivo-reflexivo, com foco nas relações sintático-semânticas no texto. Contudo, professores ainda apegam-se à tradição e consideram a terminologia linguística como principal fator inibidor da compreensão das questões.

\section{CONCLUSÃO}

A análise dos enunciados de duas questões do ENEM 2011, selecionadas por terem sido apontadas pelos alunos em dois extremos (uma muito fácil e outra muito difícil), traz à luz o problema da redação destes textos, à primeira vista, pautados pela simplicidade e desconsiderados no que se refere a sua importância para o eficaz entendimento da questão.

Da observação da atividade aponta-se que, quando o professor lê o texto enunciativo de determinada questão, comentando-o com o aluno, há grandes probabilidades de que obtenha sucesso na resposta, oferecendo-nos claro sinal de que falta a esse aluno proficiência leitora. Esta autonomia é extremamente necessária à aquisição de saberes em todas as áreas do conhecimento.

Fica bastante evidente que o enunciado da questão proposta constitui-se em elemento facilitador/dificultador, apontando para este gênero textual como potencial material de estudo, quer no que se refere à estruturação/formulação, quer no que se refere à lexicografia.

Apresenta-se-nos como material de estudo também a estruturação/formulação das alternativas, seja a prova elaborada em termos de respostas tradicionais de múltipla 
escolha, ou no formato de situações-problema cotidianas para reflexão e posterior resolução.

Tanto na elaboração do enunciado como na elaboração estrutural das alternativas, fica patente que não basta apenas ser especialista no assunto avaliado, ponto que, somado à metodologia correta da estruturação do item, constitui-se num amplo campo de pesquisa, que muito contribuirá para validação mais justa dos conhecimentos apresentados pelos alunos nas avaliações que lhes são pertinentes.

O que não se pode perder de vista é a responsabilidade assumida pelos professores no sentido de instrumentalizar os alunos em termos de conhecimentos, e a base para tanto se ancora, indiscutivelmente, na compreensão leitora. É preciso alteração substantiva tanto no que se refere às metodologias de ensino quanto à concepção de ensino e de aprendizagem subjacente ao fazer diário do professor.

\section{REFERÊNCIAS BIBLIOGRÁFICAS}

BRASIL. (2008). Ministério da Educação. PDE: Plano de Desenvolvimento da Educação: SAEB: ensino médio: matrizes de referência, tópicos e descritores. Brasília: MEC, SEB; Inep.

ENEM 2011, Caderno Amarelo, 20 dia, página 7. Disponível em:< http://enem.inep.gov.br/>. Acesso em: 20-06-2012.

Löbler, D. A. D. \& Flôres, O.C. (2010) As profundezas da compreensão: as interrelações entre interpretação, compreensão e significado. Revista Signo. Santa Cruz do Sul, v. 35, $\mathrm{n}^{\mathrm{o}}$ 59, p. 181-196, jul.-dez. Disponível em: <http://online.unisc.br/seer/index.php/signo/index>. Acesso em: 6-6-2012.

Reinaldo, M.A.M. (2006). Conhecimentos linguísticos em enunciados de provas de português: do objeto de referência científica ao objeto de ensino. Revista Intercâmbio, volume XV. São Paulo: LAEL/PUC, ISSN 1806-275X.

Solé, I. (1998). Estratégias de Leitura. Porto Alegre: Art Med.

Viana, H. M. (1976). Testes em Educação. $2^{\text {a }}$ Ed. São Paulo, IBRASA; Rio de Janeiro, FENAME.

Weisz, T. (2002). O diálogo entre o ensino e a aprendizagem. São Paulo-SP: Editora Ática. 


\section{A AUTORA}

Isabela do Nascimento Pacheco é graduada em Letras pela Faculdade de Filosofia, Ciências e Letras de Lorena, em Pedagogia pelas Faculdades Integradas de Cruzeiro e cursou Supervisão Escolar nas Faculdades Nove de Julho. Concluiu pós-graduação em gestão escolar na Unicamp. Há 22 anos atua como Professora de Língua Portuguesa na Rede Pública do Estado de São Paulo, atualmente na EE "Prof Alice Vilela Galvão", município de Canas, São Paulo, e há 32 anos, como Supervisora de Ensino na mesma Rede, Diretoria de Ensino da Região de Guaratinguetá, São Paulo. Está prevista para este ano a defesa da dissertação de mestrado com o tema "Leitura dos enunciados das situações-problema da prova do ENEM 2011”, na UNITAU - Universidade de Taubaté.

E-mail: isabelanpacheco@ hotmail.com 